\title{
A PESQUISA JURÍDICA: PARA ALÉM DA REVISÃO BIBLIOGRÁFICA
}

\author{
Priscila Tinelli Pinheiro* \\ Gilsilene Passon P. Francischetto**
}

SUMÁRIO: Introdução; 2 A permanência bistórica da pesquisa bibliográfica como resquício do tradicionalismo nos cursos de direito; 3 Alguns recursos metodológicos de aproximação do pesquisador com a realidade social; 3.1 Entrevista. 3.2 História de vida. 3.3 Observação participante. 4 Resolução $n^{\circ}$ 466/2012 e as exigências do Comitê de Ética nas pesquisas que envolvem seres humanos. 5 Considerações finais. Referências.

RESUMO: Desde a sua criação, os cursos jurídicos trazem como marcas do colonialismo a ausência da pesquisa, ou a sua restrição à revisão bibliográfica. No entanto, esta permanência histórica, fundada no tradicionalismo do ensino jurídico, precisa ser superada, tendo em vista que a complexidade da realidade social, objeto do direito, necessita da utilização de variados tipos de pesquisa para sua devida compreensão. Por meio da análise da entrevista, da história de vida e da observação participante, como técnicas alternativas à pesquisa de cunho bibliográfico, discute-se a importância da investigação no curso de direito com base no tripé ensino, pesquisa e extensão, além de verificar as formas pelas quais a pesquisa jurídica pode se aproximar da realidade social que se propõe a estudar. Objetiva-se, por último, apresentar as modalidades de entrevista, os principais traços da pesquisa do tipo observação participante e a utilização da história de vida na pesquisa jurídica, tomando por base as exigências estabelecidas pela resolução $n^{0} 466 / 12$, que instituiu a obrigatoriedade da aprovação das pesquisas que envolvem seres humanos por comitês de ética. Utilizaram-se, como principais referenciais teóricos, as obras de Verena Alberti (2004), Antônio Carlos Gil (2002), Marcos Masetto (2003) e Michel Thiollent (1998). Como principais resultados, destaca-se a necessidade de diversificação a fim de consolidar e ampliar o horizonte das pesquisas jurídicas.

PALAVRAS-CHAVES: Pesquisa; Cursos de direito; Entrevista; História de vida; Observação participante; Comitê de ética.

\footnotetext{
"Doutora em Direitos e Garantias Constitucionais pela Faculdade de Direito de Vitória (FDV). Advogada, Brasil E-mail: priscilatinelli@hotmail.com

** Pós-doutora pelo Centro de Estudos Sociais da Universidade de Coimbra. Docente titular na graduação, pós-graduação, mestrado e Doutorado da Faculdade de Direito de Vitória (FDV), Brasil.
} 


\section{JURIDICAL RESEARCH: BEYOND THE BIBLIOGRAPHICAL REVIEW}

ABSTRACT: Since their establishment, law courses retain, as a colonial residue, the lack of research and restriction to bibliographical reviews. Such historical traces, established within tradition juridical learning, should be overcome due to the complexity of social reality which requires the employment of several types of research for a deeper understanding. Through interviews, life history and participating observation, such as alternative techniques in bibliographical research, the importance of investigation in law courses is discussed, based on teaching, research and extension, and the verification of modes by which juridical research may come close to social reality under analysis. Interview modalities, the main research clues, involving participating observation and the use of life history in juridical research, are presented. They are based on requirements established by Resolution 466/12 which mandatorially instituted the approval of research involving human beings by Ethics committees. Works by Verena Alberti (2004), Antônio Carlos Gil (2002), Marcos Masetto (2003) and Michel Thiollent (1998) are the main theoretical references. Results show the necessity of diversification to consolidate and broaden the extension of juridical research.

KEY WORDS: Research; Law courses; Interviews; Life history; Participating observation; Ethics committee.

\section{LA INVESTIGACIÓN JURÍDICA: PARA MÁS ALLÁ DE LA REVISIÓN BIBLIOGRÁFICA}

RESUMEN: Desde su creación, los cursos jurídicos traen como marcas del colonialismo la ausencia de la investigación, o su restricción a la revisión bibliográfica. Sin embargo, esta permanencia histórica, fundada en el tradicionalismo de la enseñanza jurídica, necesita ser superada, teniendo en vista que la complexidad de la realidad social, objeto del derecho, necesita de la utilización de variados tipos de investigación para su debida comprensión. Por intermedio del análisis de la entrevista, de la historia de vida y de la observación participante, como técnicas alternativas a la investigación de cuño bibliográfico, se discute la importancia de la investigación en el curso de derecho con base en el trípode enseñanza, investigación y extensión, además de verificar las formas por las cuales la investigación jurídica puede acercarse de la realidad social que se propone a estudiar. Se objetiva, por último, presentar las modalidades de entrevista, los principales rasgos de la investigación del tipo observación participante y la utilización de la historia de vida en la investigación jurídica, tomando por base las exigencias establecidas por la resolución $n^{0} 466 / 12$, que instituyó la obligatoriedad de la aprobación de las investigaciones que involucran seres humanos por comités de ética. Se utilizaron, como principales referenciales 
teóricos, las obras de Verena Alberti (2004), Antonio Carlos Gil (2002), Marcos Masetto (2003) y Michel Thiollent (1998). Como principales resultados, se destaca la necesidad de diversificación con la finalidad de consolidar y ampliar el horizonte de las investigaciones jurídicas.

PALABRAS CLAVE: Investigación; Cursos de derecho; Entrevista; Historia de vida; Observación participante; Comité de ética.

\section{INTRODUÇÃO}

$\mathrm{O}$ tradicionalismo presente nas primeiras faculdades de direito instituídas no Brasil, no século XIX, o qual advém da forte influência do ensino jesuítico, possui reflexos nas diversas frentes do ensino neste curso, tais como a estrutura da aula, a hierarquização da relação entre professor e aluno, a própria seleção dos conteúdos ministrados e, especialmente, a forma pela qual essa ciência é produzida.

Em virtude do distanciamento estabelecido entre a forma de organização do ensino jurídico e a realidade social - seu principal objeto de estudo e de trabalho formaram-se juristas cada vez mais alheios e incapazes de lidar de maneira sensível com questões sociais, como as que envolvem os direitos humanos, por exemplo.

Com a pesquisa jurídica - constitutiva de uma das irradiações do ensino jurídico e do próprio tripé educacional contemplado pelo artigo 207 da Constituição Federal - não foi diferente. Isso porque é possível identificar forte permanência histórica na produção dos trabalhos científicos, a qual ocorre essencialmente por meio da pesquisa do tipo bibliográfica, ou seja, é mais uma maneira de reforçar a distância criada entre o universo jurídico e a comunidade onde ele se insere (BRASIL, 1988).

Outro fator que contribui para reforçar esta situação é justamente a tradição da pesquisa na modernidade, que tem como forte característica o distanciamento entre o próprio pesquisador e o objeto, o qual ele se propõe a pesquisar. Não se nega, ao contrário, a necessidade da separação entre o sujeito e o objeto a fim de conferir credibilidade para o estudo, porém - dentre as consequências acarretadas por esta prática - está o próprio enclausuramento das investigações, no sentido de construir uma barreira entre o pesquisador e o campo.

É como se o direito, em muitas situações, se colocasse como algo estranho à sociedade $\mathrm{e}$, por conseguinte, não pudesse ser aplicado de maneira satisfatória às demandas que lhe são apresentadas. Esse estranhamento decorre, por sua vez, da 
forma pela qual o conteúdo jurídico é produzido, pois há diversas teorias e leis que não refletem necessariamente as demandas sociais do povo brasileiro.

Surge, então, por meio da mudança na forma pela qual a pesquisa jurídica tem sido conduzida ao longo dos anos, a possibilidade de driblar o dogmatismo característico deste estudo fundado na legislação. Tendência esta que reflete diretamente a influência do positivismo jurídico, o qual preconiza a experimentação como o único caminho possível para se construir o conhecimento e, por conseguinte, se chegar à "verdade". Logo, limita-se a pesquisa em caixas pré-determinadas pela exatidão deste conhecimento almejado, que não se adequam à realidade observada pelas ciências sociais, como o direito, pelo fato de não comportar tamanha exatidão, típica das ciências exatas.

Torna-se importante que essas pesquisas tentem, de certa forma, reduzir esta distância entre a forma pela qual o direito cuida da sociedade por meio da atuação de seus profissionais. Desta forma, com a finalidade de estabelecer esta aproximação - permitindo que os estudiosos do direito conheçam mais de perto a situação que eles se propõem a analisar - e, em certa medida, impedir que os trabalhos acadêmicos estejam desconexos com a realidade social, é imprescindível a busca por outros meios para se fazer pesquisa.

Neste sentido, há inúmeras outras formas de se produzir conhecimento que vão além dessa tradição do uso da pesquisa bibliográfica e que, ao mesmo tempo permitem um diálogo entre os sujeitos investigados e o pesquisador. A utilização, por exemplo, de técnicas como a entrevista - em suas diversas modalidades - a história de vida - como uma extensão da entrevista - e da observação participante - como um acompanhamento pelo pesquisador de maneira mais ativa do conteúdo pesquisado - pode contribuir de maneira significativa para a legitimidade do discurso científico.

Optou-se por trabalhar com a entrevista - que, apesar de ainda ser pouco explorado, aparece em algumas pesquisas jurídicas - e outros dois tipos poucos conhecidos nesta área, que são: a história de vida - como uma extensão da entrevista - e a observação participante - que permite a interação maior do pesquisador com os fenômenos sociais e os seus atores.

A escolha por estes tipos de pesquisa se deu com a finalidade de apresentar outros caminhos possíveis, que permitem inclusive uma aproximação dos profissionais deste meio com o seu objeto de estudo e de trabalho, mas que ainda são pouco 
usuais nas faculdades de direito. Pretende-se demonstrar, portanto, que permanecer nesta forma de produzir ciência é correr o risco de reproduzir o discurso desconexo da realidade social.

Somada à importância de se expandir os horizontes da pesquisa nas ciências humanas e sociais - em especial a jurídica - passou-se a adotar também para as pesquisas desenvolvidas nestas áreas, a análise dos comitês de ética, a qual era tradicionalmente restrita à área da saúde. Com isso, as pesquisas que, porventura, envolvam seres humanos devem passar pelo crivo do respectivo comitê de ética, os quais se submetem aos parâmetros estabelecidos pela resolução $\mathrm{n}^{0} 466 / 2012^{03}$, do Ministério da Saúde, para a realização deste tipo de investigação, de forma a conferir maior cientificidade a estes estudos.

A principal questão, então, colocada para aquele que se propõe a investigar é adequar o mecanismo de pesquisa de forma a buscar alternativas para que o conhecimento teórico esteja entrelaçado, no seu trabalho, ao ambiente externo ao acadêmico. Assim, o presente trabalho se destinará à análise - a partir do estudo da entrevista, da observação participante e das histórias de vida - dos possíveis caminhos, além da revisão bibliográfica, para a realização da pesquisa no direito.

\section{A PERMANÊNCIA HISTÓRICA DA PESQUISA BIBLIOGRÁFICA COMO RES- QUÍCIO DO TRADICIONALISMO NOS CURSOS DE DIREITO}

A criação dos primeiros cursos jurídicos no Brasil ocorreu para atender uma demanda pela profissionalização dos bacharéis em direito, tendo em vista a necessidade de ocupação de cargos burocráticos no país.

Neste sentido, Masetto ${ }^{04}$ afirma que

[...] os cursos superiores e, posteriormente, as faculdades criadas e instaladas no Brasil, desde seu início e nas décadas posteriores, voltaram-se diretamente para a formação de profissionais que exerceriam uma determinada profissão. Currículos seriados, programas fechados, que constavam unicamente das disciplinas que interessavam imediata e diretamente ao exercício daquela profissão e procuravam formar profissionais competentes em uma determinada área ou especialidade.

\footnotetext{
${ }^{03}$ BRASIL. Resolução n. 466, de 12 de dezembro de 2012. Disponível em: http://bvsms.saude.gov.br/bvs/saudelegis/cns/2013/res0466_12_12_2012.html. Acesso em: 16 out. 2017.

${ }^{04}$ MASETTO, Marcos. Professor universitário: um profissional da educação na atividade docente. In .: MASETTO, Marcos. Docência na universidade. 6. ed. Campinas: Papirus, 2003. p. 10.
} 
Contudo, as exigências da sociedade brasileira modificaram-se de tal forma que este "encastelamento" do ensino jurídico se tornou insuficiente para atender às demandas postas sob a análise dos juristas atuais. As relações sociais, por sua vez, atingiram tamanho grau de complexidade que um ensino desconexo da realidade, como é característico do tradicionalismo europeu importado pelo modelo dos cursos brasileiros, apresenta-se como ultrapassado.

Diante desta realidade complexa é preciso compreender que

[...] as faculdades de Direito não são apenas núcleos formadores de profissionais, tecnicamente considerados, mas também, e, sobretudo, de cidadãos que têm a responsabilidade de atuar de maneira sensível e comprometida com as transformações sociais e com a dignidade dos indivíduos ${ }^{05}$.

Numa tentativa, então, de cumprir essa exigência, a Reforma Educacional de 1968 instituiu o tripé educacional constituído pelo ensino, pela pesquisa e pela extensão, já que é uma necessidade de todo o ensino superior ampliar sua formação (BRASIL, 1988). A própria Constituição Federal de 1988 determinou, em seu artigo 207, o dever de obediência das universidades ao princípio da indissociabilidade entre o ensino, a pesquisa e a extensão, o que indica, expressamente, que o ensino superior deve pautar a construção dos seus currículos nestes três pilares essenciais (BRASIL, 1988).

É importante ressaltar que antes de se pensar na implementação deste tripé, sequer havia menção à pesquisa nas faculdades de direito, visto que o foco da educação jurídica naquela época era o estudo da legislação. Assim, o mais próximo que os estudantes chegavam da pesquisa jurídica era por meio dos manuais e dos livros elaborados pelos próprios professores para servirem de referência. Neste sentido, a portaria $n^{0}$ 1.886/94, do Ministério da Educação, foi um marco legal importante, pois apenas com a sua instituição, a qual estabeleceu as diretrizes curriculares e o conteúdo mínimo dos cursos jurídicos, é que houve a tentativa de implementação do tripé ensino, pesquisa e extensão, dentre outras inovações trazidas pela legislação, no ensino do direito.

Com um ensino ainda preso às raízes arcaicas do legalismo e do tecnicismo impede-se que o aluno do direito leia o ordenamento jurídico em conjunto com as

\footnotetext{
${ }^{05}$ FRANCISCHETTO, Gilsilene Passon P. Em busca de novos saberes: uma aproximação entre o ensino jurídico e a pedagogia. In: FRANCISCHETTO, Gilsilene Passon P.. Ensino jurídico e pedagogia: em busca de novos saberes. Curitiba. CRV, 2010. p. 13-52. p. 14.
} 
práticas sociais, o que, por conseguinte, engessa, tanto o conhecimento jurídico, quanto o aluno na legislação ${ }^{06}$.

O pilar da pesquisa ${ }^{07}$, que é o enfoque deste trabalho, possui grande contribuição no abandono da visão do ensino como mera mercadoria e no cumprimento efetivo do seu papel: "[...] desenvolvimento social, econômico e cultural comum e de direito de todos" $"$.

Esta mudança de paradigma prescinde, igualmente, de uma transição do modelo cartesiano $0^{09}$ de pesquisa para um modelo que comporte a pluralidade e complexidade das relações e dos fatos sociais, que é o objeto das ciências sociais, como o direito. Este modo de se construir o conhecimento é fundamental para as ciências naturais, já que seu objeto de investigação permite esse grau de exatidão, o que, por outro lado, não condiz com a análise dos fatos humanos.

A própria maneira com que os pesquisadores destas áreas travam relações com seus respectivos objetos de investigação é diversa, uma vez que o sujeito da pesquisa jurídica não pode, por exemplo, "[...] frente aos fatos sociais, ter essa objetividade, apagar-se desse modo. Frente aos fatos sociais, tem preferências, inclinações, interesses particulares; interessa-se por eles e os considera a partir de seu sistema de valores" $"$.

Nota-se que a interação estabelecida entre sujeito e objeto, nas ciências humanas e sociais, difere-se fundamentalmente, o que reflete - por conseguinte na obtenção da "veracidade" que pode ser obtida em uma e noutra seara. Sobre a possibilidade de submeter os fatos sociais à verificação empírica, Laville e Dione ${ }^{11}$ analisam o tema da seguinte forma:

\footnotetext{
${ }^{06}$ FRANCISCHETTO, Gilsilene Passon P. Em busca de novos saberes: uma aproximação entre o ensino jurídico e a pedagogia. In: FRANCISCHETTO, Gilsilene Passon P. Ensino jurídico e pedagogia: em busca de novos saberes. Curitiba. CRV, 2010. p. 13-52. p. 19.

${ }^{07}$ Aliada à pesquisa, como um mecanismo essencial para a produção de um diagnóstico da realidade social, está a extensão em complemento ao tripé da educação. Este terceiro componente, compõe-se por um conjunto de atividades que possibilita o estabelecimento de uma interação entre a academia e a sociedade na qual está inserida. Destaca-se que o fim para o qual a extensão se destina somente é atingido à medida em que o saber produzido no âmbito das salas de aula torna-se relevante e contribui para o desenvolvimento social. Isso porque é forma que a universidade possui de ultrapassar os seus limites geográficos e estabelecer um contato com a comunidade em que se insere.

${ }^{08}$ COSTA, Everton de Brito Oliveira; RAUBER, Pedro. História da educação: surgimento e tendências atuais na universidade no Brasil. Revista Jurídica UNIGRAN. Dourados, MS, v. 11, n. 21, jan./jun, 2009. p. 250.

${ }^{09} \mathrm{O}$ modelo cartesiano de pesquisa pode ser compreendido como aquele que se restringe à pesquisa com fôlego teórico-doutrinário, vale dizer, parte-se do exame dos referenciais teóricos e de suas análises teóricas.

${ }^{10}$ LAVILLE, Christian; DIONNE, Jean. A construção do saber: manual de metodologia da pesquisa em ciências humanas. Tradução de Heloísa Monteiro e Francisco Settineri. Porto Alegre: Artmed, 1999. p. 34.

${ }^{11}$ Ibidem, 1999. p. 35.
} 
Em ciências naturais, considera-se que um conhecimento é válido se, repetindo a experiência tantas vezes quanto necessário nas mesmas condições, chega-se aos mesmos resultados. Como fazer quando, em ciências humanas, o número e a complexidade dos fatores em questão tornam difícil e, às vezes, impossível o fato de reconhecê-los com exatidão e, então, controlá-los? Quando os objetos de estudo permanecem livres, podem, durante o percurso, modificar o desenrolar da experimentação? Quando os pesquisadores, devido à sua influência, podem, de um momento a outro, mudar o curso de uma experimentação? O verdadeiro, em ciências humanas, apenas pode ser um verdadeiro relativo e provisório.

É o paradigma da ciência moderna que ainda se faz presente, enaltecendo a utilização do método e da experimentação como formas únicas de obtenção da verdade, componente principal do trinômio da ciência. Diante dos fenômenos sociais, este modelo epistemológico e de racionalidade mostra-se insuficiente, sendo necessária sua substituição por um novo paradigma.

Busca-se, especialmente no direito, a construção de "[...] um conhecimento holístico, capaz de contribuir para a necessária aproximação entre o pesquisador e o mundo social no qual está inserido" ${ }^{2}$. Neste sentido, a comprovação empírica não pode ser um fator determinante para retirar o caráter científico do direito, pois os pressupostos da ciência moderna não são suficientes para a construção de teorias jurídicas capazes de analisar a realidade social tal qual ela se apresenta atualmente.

À luz da transição do paradigma científico, Boaventura de Sousa Santos ${ }^{13}$ descreve que " $[. .$.$] o paradigma a emergir dela não pode ser apenas um paradigma$ científico (o paradigma de um conhecimento prudente), tem de ser também um paradigma social (o paradigma de uma vida decente)". Isso significa que mais do que conferir um suporte epistemológico, este novo paradigma deve se fazer presente no âmbito social, de forma a ultrapassar os limites da produção mecânica do conhecimento.

Não se nega a importância que a pesquisa de cunho bibliográfico tem para a compreensão da seara jurídica, na medida em que a revisão bibliográfica opera no sentido de

${ }^{12}$ DUARTE, Ícaro de Souza; CRUZES, Maria Soledad Soares. A metodologia da pesquisa no Direito e Boaventura de Sousa Santos. Cadernos de Ciências Sociais Aplicadas, Vitória da Conquista, n. 8, 2009. p. 44.

${ }^{13}$ SANTOS, Boaventura de Sousa Santos. Um discurso sobre as ciências. 5. ed. São Paulo: Cortez, 2008. p. 60 
[...] revisar todos os trabalhos disponíveis, objetivando selecionar tudo o que possa servir em sua pesquisa. Nela tenta encontrar essencialmente os saberes e as pesquisas relacionadas com sua questão; deles se serve para alimentar seus conhecimentos, afinar suas perspectivas teóricas, precisar e objetivar seu aparelho conceitual. Aproveita para tornar ainda mais consciente e articuladas suas intenções e, desse modo, vendo como outros procederam em suas pesquisas, vislumbrar sua própria maneira de fazê-lo ${ }^{14}$.

Trata-se de uma fase importante para o pesquisador, pois é neste momento que ele tem a oportunidade de aprofundar sua base teórica que constituirá todo o suporte teórico do seu trabalho. Desenvolvida a partir da consulta a livros, artigos científicos e diversos outros materiais, esta técnica de pesquisa contribui para a ampliação do universo de pesquisa, já que permite ao sujeito pesquisar dados construídos a priori.

No entanto, vislumbra-se a possibilidade dela se aliar a outras tantas técnicas de pesquisa que tenham por objetivo a aproximação com a realidade social. Porém, acredita-se que o isolamento do pesquisador, principalmente nas áreas em que se estudam as relações sociais, é insuficiente para promover um saber significativo.

Diante destes pressupostos acerca da incompatibilidade entre o modelo cartesiano de pesquisa e o objeto estudado pelo direito, enquanto ciência social, é preciso buscar, então, a desconstrução dos muros que separam - em muitas situações - o direito e o seu estudante - da realidade social por meio do fortalecimento da pesquisa. Sendo necessárias, inclusive, profundas modificações no seu modo de fazer, como a maior utilização de outros tipos de pesquisa, para além da revisão bibliográfica, as quais serão apresentadas no tópico seguinte.

\section{ALGUNS RECURSOS METODOLÓGICOS DE APROXIMAÇÃO DO PESQUISA- DOR COM A REALIDADE SOCIAL}

Os pesquisadores das ciências sociais e, nelas está incluído o direito, devem se atentar para o trabalho com teorias e métodos que promovam a valorização da

${ }^{14}$ LAVILLE, Christian; DIONNE, Jean. A construção do saber: manual de metodologia da pesquisa em ciências humanas. Tradução de Heloísa Monteiro e Francisco Settineri. Porto Alegre: Artmed, 1999. p. 112. 
experiência humana, a qual tem por característica a complexidade ${ }^{15}$.

Neste contexto, ressalta-se um dos motivos pelo qual ela é singular em relação às demais áreas do conhecimento.

a pesquisa em ciências sociais lida com pessoas e seus contextos de vida, bem como com questões filosóficas relacionadas à natureza do conhecimento e da verdade (epistemologia), dos valores (axiologia) e do ser (ontologia) que embasam os critérios e as atividades humanas ${ }^{16}$.

Os trabalhos investigativos no âmbito jurídico devem, então, "[...] revalorizar os estudos humanísticos, ou seja, a transição paradigmática na ciência do Direito inclui a transformação, mas não o abandono, da dogmática jurídica, buscando-se mais a aplicação da zetética e hermenêutica jurídica"17. Além disso, na pesquisa jurídica, o conhecimento deve se voltar à concepção humanística, por isso é necessário o emprego da pluralidade de técnicas, em especial, aquelas que tenham por característica a aproximação com o objeto a ser estudado: as relações sociais.

Apesar da importância inegável da pesquisa de cunho teórico e bibliográfico, em muitos estudos, ela precisa estar aliada a outras técnicas de investigação que proporcionem, ao pesquisador, um contato maior com o seu objeto de análise. Por isso, estabelecer essa proximidade com os fenômenos sociais cria, para o pesquisador, o desafio de correlacionar o suporte teórico com a realidade fática.

O campo de pesquisa, nesta perspectiva, é uma representação empírica da realidade "[...] a ser estudada a partir das concepções teóricas que fundamentam o objeto da investigação" ${ }^{18}$. Então, ir a campo é uma ação que expõe o pesquisador a inúmeras variáveis que, muitas vezes, colocam em xeque a própria hipótese de pesquisa.

E a contribuição do campo de pesquisa é justamente essa: abrir os olhos do pesquisador para as múltiplas possibilidades da realidade social, as quais podem

\footnotetext{
${ }_{15}$ SOMEKH, Bridget; et al. Pesquisa nas ciências sociais. In: SOMEKH, Bridget; LEWIN, Cathy. (org.) Teoria e Métodos de Pesquisa Social. Tradução de Ricardo A. Rosenbusch. Vozes: Petrópolis, 2015. p. 27.

${ }^{16}$ SOMEKH, Bridget; et al. Pesquisa nas ciências sociais. In: SOMEKH, Bridget; LEWIN, Cathy. (org.) Teoria e Métodos de Pesquisa Social. Tradução de Ricardo A. Rosenbusch. Vozes: Petrópolis, 2015. p. 27.

${ }^{17}$ DUARTE, Ícaro de Souza; CRUZES, Maria Soledad Soares. A metodologia da pesquisa no Direito e Boaventura de Sousa Santos. Cadernos de Ciências Sociais Aplicadas, Vitória da Conquista, n. 8, 2009, p. 39.

${ }^{18}$ CRUZ NETO, Octavio. O trabalho de campo como descoberta e criação. In: DESLANDES, Suely Ferreira; CRUZ NETO, Octavio; GOMES, Romeu; MINAYO, Maria Cecilia de Souza (org.). Pesquisa social: teoria, método e criatividade. Petrópolis: Vozes, 1994. p. 53.
} 
estar encobertas pela distância entre eles. O pesquisador deve assumir uma postura mais aberta na sua imersão ao campo, no sentido de se despir de suas pré-concepções para permitir ser contrariado e, com isso, dar chances aos fenômenos sociais se revelarem em sua completude a ele. Com relação à postura do pesquisador em relação à problemática a ser estudada, Cruz Neto ${ }^{19}$ chama a atenção para o fato de que

Às vezes o pesquisador entra em campo considerando que tudo que vai encontrar serve para confirmar o que ele considera já saber, ao invés de compreender o campo como possibilidade de novas revelações. Esse comportamento pode dificultar o diálogo com os elementos envolvidos no estudo na medida em que permite posicionamentos de superioridade e de inferioridade frente ao saber que se busca entender.

No sentido de buscar esta aproximação e permitir a interação com a figura do pesquisador, faz-se necessária uma ambientação prévia dos componentes da pesquisa. É como se a construção de uma relação de confiança, ainda que mínima, fosse o primeiro passo para os pesquisadores que optam pela utilização de técnicas de pesquisa que tenham por finalidade a aproximação com a realidade social investigada.

A relação de confiança se torna uma condição necessária para que os pesquisadores de ciências sociais realizem pesquisas de alta qualidade ${ }^{20}$. Tendo em vista que o objeto desta ciência é composto pelos próprios fenômenos sociais, o fato de o pesquisador se enclausurar em bibliotecas, ou mesmo se prender aos referenciais existentes gera uma tendência à reprodução do conhecimento.

É preciso, neste sentido, buscar além dos muros das universidades a maneira pela qual a realidade social se constitui, sob pena de serem produzidas pesquisas com um olhar incompleto, visto que há maior chance de os detalhes serem descobertos pelo pesquisador que se propõe a ir a campo.

A importância da ambientação é tanta que dificilmente um pesquisador que não se prepara para uma imersão ao campo conseguirá obter respostas completas,

\footnotetext{
${ }^{19}$ CRUZ NETO, Octavio. O trabalho de campo como descoberta e criação. In: DESLANDES, Suely Ferreira; CRUZ NETO, Octavio; GOMES, Romeu; MINAYO, Maria Cecilia de Souza (org.). Pesquisa social: teoria, método e criatividade. Petrópolis: Vozes, 1994. p. 55-56.

${ }^{20}$ SOMEKH, Bridget et al. Pesquisa nas ciências sociais. In: SOMEKH, Bridget; LEWIN, Cathy. (org.) Teoria e Métodos de Pesquisa Social. Tradução de Ricardo A. Rosenbusch. Vozes: Petrópolis, 2015. p. 30.
} 
ou mesmo vislumbrar a totalidade dos fenômenos sociais, pois sempre haverá uma barreira a ser transposta. Esse contato prévio deve ser estabelecido com vistas a conhecer os detalhes de uma determinada comunidade, ou grupo social que se propõe a analisar.

Mais do que uma empatia entre os interlocutores, deve ocorrer uma aproximação significativa, a fim de facilitar que os entrevistados, por exemplo, revelem-se ao pesquisador. E, neste sentido, são vários os fatores que podem aproximar os envolvidos na investigação, tais como as vestimentas, a linguagem, os comportamentos, por isso é preciso um cuidado maior com a etapa inicial, já que ela será determinante para as fases seguintes do trabalho.

A grande dificuldade com a qual o pesquisador que se propõe a ir a campo, utilizando-se das mais variadas técnicas de pesquisa, constitui-se no "[...] fato de os relacionamentos serem orgânicos e não estáticos, a confiança ser um conceito incerto e os seres humanos nunca revelarem (nem podem revelar) tudo o que têm em mente $[\ldots]^{\prime 21}$. Estabelecer, portanto, uma relação de confiança requer que os interlocutores se identifiquem, ainda que minimamente, com o pesquisador.

São as "[...] barreiras e as aberturas psicossociais operantes no encontro e na comunicação [...]"22 entre os que investigam e os que são "investigados" que precisam ser quebradas e construídas, respectivamente. Apresentadas como alternativas para a superação da desconfiança que recai sobre o pesquisador estrangeiro que se apresenta ao grupo de análise. É o "cafezinho" que o pesquisador deve aceitar quando lhe for oferecido, procurar se sentar junto aos interlocutores nos horários de descanso para uma conversa informal, fazer refeições em conjunto com o grupo, utilizar os mesmos banheiros, por exemplo.

$\mathrm{Na}$ busca pela diversidade na maneira pela qual a pesquisa jurídica tem sido realizada desde os primeiros cursos de direito instituídos no Brasil e, diante da necessidade de adequar a produção do conhecimento jurídico às mudanças sociais, torna-se imprescindível compreender as especificidades de outras técnicas de pesquisa, tais como a entrevista, nas suas modalidades estruturada e semiestruturada, a história de vida e a observação participante.

\footnotetext{
${ }^{21}$ SOMEKH, Bridget; et al. Pesquisa nas ciências sociais. In: SOMEKH, Bridget; LEWIN, Cathy. (org.) Teoria e Métodos de Pesquisa Social. Tradução de Ricardo A. Rosenbusch. Vozes: Petrópolis, 2015. p. 27.

${ }^{22}$ COSTA, Fernando Braga da. Homens invisíveis: relatos de uma humilhação social. São Paulo: Globo, 2004 , p. 57.
} 


\subsection{ENTREVISTA}

Dentre os possíveis caminhos que a pesquisa jurídica pode seguir, a entrevista é a primeira técnica eleita para compor a presente análise. Sendo uma das formas mais básicas de contato entre os envolvidos na pesquisa, a entrevista permite ao pesquisador colher dados objetivos e subjetivos.

Os objetivos, na visão de Cruz Neto ${ }^{23}$ são aqueles que "[...] podem ser também obtidos através de fontes secundárias, tais como censos, estatísticas e outras formas de registros". Em contrapartida, os dados subjetivos não se encontram em registros escritos, ou mesmo no ambiente observado, mas nas experiências e no pensamento dos entrevistados. Pode-se dizer, então, que "[...] o segundo tipo de dados se relaciona aos valores, às atitudes e às opiniões dos sujeitos entrevistados" ${ }^{\prime 2}$.

Schostak e Barbour ${ }^{25}$ salientam a importância da entrevista ao afirmar que ela, mais do que uma simples ferramenta disponível para o pesquisador, assemelha-se a uma "[...] broca para penetrar mais fundo nas estruturas discursivas que sustentam as palavras dos 'indivíduos'. É também um modo de ver ou, melhor, uma condição para ver o que quer que seja".

Assim como as demais técnicas que serão apresentadas a seguir, a entrevista requer um esforço do sujeito para estabelecer com os participantes certa relação de proximidade. Com o objetivo de obter "[...] informações importantes e de compreender as perspectivas e experiências das pessoas entrevistadas" ${ }^{\prime 26}$, o grau de proximidade faz com que eles se sintam à vontade no decorrer da investigação para responder de forma mais fidedigna aos questionamentos propostos.

Compreendida como um diálogo entre dois interlocutores, a entrevista é conduzida, em sua maior parte de um roteiro, o qual possui características diversas a depender da modalidade de entrevista utilizada. E o que diferencia basicamente as duas modalidades de entrevista é a liberdade do sujeito entrevistador.

A entrevista que segue a modalidade estruturada é mais fechada, no sentido de não dar margens para o entrevistador ampliar o rol de questões previamente

\footnotetext{
${ }^{23}$ CRUZ NETO, Octavio. O trabalho de campo como descoberta e criação. In: DESLANDES, Suely Ferreira; CRUZ NETO, Octavio; GOMES, Romeu; MINAYO, Maria Cecilia de Souza (org.). Pesquisa social: teoria, método e criatividade. Petrópolis: Vozes, 1994. p. 57.

${ }^{24}$ Idem.

${ }^{25}$ SCHOSTAK, John; BARBOUR, Rosaline S. Entrevista e grupos-alvo. In: SOMEKH, Bridget; LEWIN, Cathy. (org.) Teoria e Métodos de Pesquisa Social. Tradução de Ricardo A. Rosenbusch. Petrópolis: Vozes, 2015. p. 102.

${ }^{26}$ MARCONI, Marina de Andrade; LAKATOS, Eva Maria. Metodologia científica. 4. ed. São Paulo: Atlas, 2004. p. 94.
} 
formulado. Assim, "o pesquisador não é livre para adaptar suas perguntas a determinada situação, de alterar a ordem dos tópicos ou de fazer outras perguntas"27.

Por outro lado, a modalidade semiestruturada pode ser caracterizada como aquela em que "[...] o entrevistador tem liberdade para desenvolver cada situação em qualquer direção que considere adequada" ${ }^{28}$. Esta modalidade permite que o pesquisador conheça de maneira ampla as questões que se propôs a investigar, tendo em vista que a elaboração das perguntas ocorre de forma mais aberta, o que possibilita ao entrevistado discorrer em sua resposta sobre o tema. Por sua vez, o entrevistador tem a oportunidade de ir além daquele roteiro prévio, incluindo até mesmo novos questionamentos durante a entrevista, quando achar necessário.

No entanto, é preciso tomar certo cuidado com a postura adotada neste rito investigatório, porque não se permite ao entrevistador influenciar as respostas dos entrevistados de maneira a conduzir a entrevista para confirmar as hipóteses da pesquisa. Ou seja,

[...] o entrevistador deveria adotar a postura de quem escuta de modo que assemelha a linguagem aos modos do entrevistado, sem impor nem objetivar a pessoa convidada para falar. Assim há maior possibilidade de as opiniões dos entrevistados emergirem, pois suas vozes estão livres do poder impositivo da pesquisa. Com isto, os dados colhidos e as análises que se seguem estrariam fundamentados nas experiências dos entrevistados e não nas exigências da pesquisa ${ }^{29}$.

O cuidado com a realização da entrevista deve ocorrer até mesmo com o local em que será empregada a técnica, o qual deve deixar o entrevistado mais à vontade. Torna-se importante, neste sentido, que não haja constrangimento em virtude, por exemplo, da presença de outras pessoas além do entrevistador a fim de que se estabeleça o sigilo da conversa desde o primeiro momento.

Da mesma forma, o uso de recursos tecnológicos, como o gravador, somente pode ocorrer com a expressa anuência do entrevistado. Além da autorização para a gravação da conversa, o pesquisador deve conceder o direito de paralisá-la no

\footnotetext{
${ }^{27}$ MARCONI, Marina de Andrade; LAKATOS, Eva Maria. Metodologia científica. 4. ed. São Paulo: Atlas, 2004. p. 94.

${ }^{28}$ Ibidem, 2004. p. 279.

${ }^{29}$ SCHOSTAK, John; BARBOUR, Rosaline S. Entrevista e grupos-alvo. In: SOMEKH, Bridget; LEWIN, Cathy. (org.) Teoria e Métodos de Pesquisa Social. Tradução de Ricardo A. Rosenbusch. Vozes: Petrópolis, 2015. p. 101.
} 
momento em que o entrevistado assim o desejar, a fim de que as questões éticas da pesquisa não sejam comprometidas. Pela facilidade que a gravação das falas oferece ao pesquisador, a sua utilização tornou-se muito comum, pois conserva "[...] na narração uma vivacidade de que o simples registro no papel as despojava, uma vez que a voz do entrevistado, suas entonações, suas pausas, seu vai-e-vem no que contava constituíam outros tantos dados para estudo" ${ }^{30}$.

Outro ponto que precisa ser observado pelo entrevistador refere-se à fase anterior à indagação, qual seja a elaboração do rol de perguntas para compor a entrevista. Isto porque a escolha de um vocabulário adequado também é imprescindível para atingir a finalidade para a qual a técnica de pesquisa se propõe. É muito comum que, a depender do perfil assumido pelo entrevistado, a linguagem precise ser adaptada, pois a depender da situação, o grau de tecnicismo utilizado na redação das perguntas pode ser um fator decisivo não só para a compreensão dos questionamentos, como também para o afastamento dos envolvidos na pesquisa.

Destacam-se dois componentes importantes, não só para a entrevista, mas para as demais técnicas que se destinarem à coleta de dados, inclusive as que serão expostas nos tópicos seguintes, são eles: a "ficha de informante" e o "caderno de campo ou diário de pesquisa" ${ }^{1}$. O primeiro deles, a "ficha de informante", nada mais é do que uma descrição do perfil social do indivíduo entrevistado ou analisado, que contém a idade, a profissão, a quantidade de filhos, dentre outras informações que o pesquisador julgar necessárias para compor sua análise. Compõe-se de informações objetivas que não comportam a manifestação de opinião por parte dos interlocutores $^{32}$.

O segundo, cuja nomenclatura mais usual é a de "diário de pesquisa/campo", é formado pelas impressões obtidas ao longo da imersão no campo. A fim de que o pesquisador tenha condições de retratar com maior riqueza de detalhes, torna-se importante que ele faça anotações sobre as condições em que a entrevista foi realizada, o seu tempo de duração, emoções emitidas pelo próprio entrevistado, pelos demais integrantes daquele ambiente, ou mesmo dos sentimentos que o pesquisador obteve na realização da pesquisa.

\footnotetext{
${ }^{30}$ QUEIROZ, Maria Isaura Pereira de. Variações sobre a técnica de gravador no registro da informação viva. São Paulo: T. A. Queiroz, 1991. p. 02

${ }^{31}$ Nomenclaturas utilizadas por Maria Isaura Pereira de Queiroz no livro intitulado "Variações sobre técnica de gravador no registro da informação viva" (1991).

${ }^{32}$ QUEIROZ, Maria Isaura Pereira de. Variações sobre a técnica de gravador no registro da informação viva. São Paulo: T. A. Queiroz, 1991. p. 64.
} 
Sobre o seu conteúdo, Queiroz ${ }^{33}$ revela que

As observações do caderno de campo esclarecem mudanças perceptíveis das entrevistas, e atribuíveis às condições específicas em que se realizaram; também contêm mais detalhes descritivos e pessoas acerca do informante; encerram as particularidades do relacionamento entre pesquisador e informante; e contêm as observações a respeito da aplicação da técnica, todas as vezes que esta foi posta em prática, suas facilidades e dificuldades, seus aspectos positivos, satisfatórios, negativos. Seja com referência às características do informante, às condições das entrevistas, às relações entre informante $\mathrm{e}$ pesquisador, às impressões e emoções de ambos, aos detalhes da aplicação técnica, seu conteúdo ganha outro significado e importância quando, ultrapassando a simples descrição, se reveste de um significado crítico.

Apesar de ser deixado de lado por alguns pesquisadores, em virtude do seu caráter subjetivo, estes registros são imprescindíveis, tanto para o pesquisador no momento posterior ao campo, para que possa construir sua análise com maior veracidade, quanto para os leitores da pesquisa, os quais terão uma visão holística da realidade social estudada possibilitando melhor compreensão do que se propôs a pesquisar.

\subsection{HISTÓRIA DE VIDA}

Um segundo exemplo de técnica de pesquisa proposto para a utilização na área do direito, é o denominado história de vida. Tal instrumento consiste num dos desdobramentos possíveis do trabalho de história oral e pode ser utilizado, por exemplo, para traçar a trajetória dos sujeitos submetidos à investigação.

A história oral, por sua vez, "[...] é um termo amplo que recobre uma quantidade de relatos a respeito de fatos não registrados por outro tipo de documentação, ou cuja documentação se quer completar"”ł . Desta forma, ela pode "[...] captar a experiência efetiva dos narradores, mas destes também recolhe tradições e mitos,

${ }_{33}$ QUEIROZ, Maria Isaura Pereira de. Variações sobre a técnica de gravador no registro da informação viva. São Paulo: T. A. Queiroz, 1991. p. 64.

${ }^{34}$ Ibidem, 1991. p. 5. 
narrativas de ficção, crenças existentes no grupo, assim como relatos que contadores de histórias, poetas, cantadores inventam num momento dado" 35 .

Como uma espécie do trabalho de história oral, a história de vida se aproxima da entrevista pelo fato de que ambas as técnicas se constituem por meio do diálogo entre os interlocutores. Contudo, a especificidade da história de vida é traduzida pelo seu objetivo: construção do vínculo das pessoas entrevistadas com suas memórias. De modo a permitir a extração do conteúdo necessário para a formação das suas respectivas identidades ${ }^{36}$, as pessoas são conduzidas a relatar suas principais memórias para compor a pesquisa e, com isso, retratar sua trajetória de vida ao pesquisador.

Esse resgate se faz necessário em muitos estudos que buscam compreender mais a fundo a organização de determinada comunidade, por exemplo, ou a estrutura de grupos sociais, de trabalho. Em contraposição à entrevista, que além de permitir que o entrevistador dirija o diálogo, a história de vida possibilita maior interação dos interlocutores, uma vez que

[...] quem decide o que vai relatar é o narrador, diante do qual o pesquisador deve se conservar tanto quanto possível silencioso. Não que permaneça ausente do colóquio, porém suas interferências devem ser reduzidas, pois o importante é que sejam captadas as experiências do entrevistado. Este é quem determina o que é relevante ou não narrar, ele é que detém o fio condutor. Nada do que relata pode ser considerado supérfluo, pois tudo se cadeia para compor e explicar sua existência ${ }^{37}$.

Os relatos orais extraídos do regime metodológico de histórias de vida possuem uma gama de possibilidades para o pesquisador, tendo em vista a riqueza que esta técnica fornece à pesquisa na área das ciências sociais. Assim, por mais simples que um relato pareça - num primeiro momento - o trabalho do pesquisador consiste num esforço de juntar as peças deste quebra-cabeça que lhe foi apresentado de maneira a montar um grande quadro acerca da vida do entrevistado.

\footnotetext{
${ }^{35}$ QUEIROZ, Maria Isaura Pereira de. Variações sobre a técnica de gravador no registro da informação viva. São Paulo: T. A. Queiroz, 1991. p. 5.

${ }^{36}$ BOSI, Ecléa. O tempo vivo da memória: ensaios de psicologia social. 3. ed. São Paulo: Ateliê, 2003. p. 16.

${ }^{37}$ QUEIROZ, Maria Isaura Pereira de. Variações sobre a técnica de gravador no registro da informação viva. São Paulo: T. A. Queiroz, 1991. p. 8.
} 
No entanto, o relato não se apresenta como uma linha reta para o pesquisador, pois a narrativa contém a própria complexidade do acontecimento ${ }^{38}$, cabendo ao interlocutor fazer os respectivos encaixes. A seleção deste emaranhado de memórias requer igualmente um esforço interpretativo do sujeito da pesquisa, de maneira que seja evitado que os fatos relatados passem despercebidos de sua análise.

Ao fazer uso desta técnica, o sujeito busca que as narrativas sejam feitas de maneira mais livre possível, atingindo inclusive o interior dos entrevistados para que seja facilitada a construção de sua trajetória de vida e da sua identidade com maior veracidade. Almeja-se alcançar, neste sentido,

[...] um discurso seguro, que não vivesse o enigma das coisas narradas, apressando conclusões e servindo-se de estereótipos ou opiniões já consagradas, corre sérios riscos de cair e deter-se em ideologia. Os lapsos e as incertezas dos depoentes podem ser o selo de autenticidade numa entrevista ${ }^{39}$.

É como se reviver aqueles momentos, por meio dos relatos orais, permitisse alimentar o próprio imaginário com fatos que, na maior parte das vezes, encontramse adormecidos na imensidão da mente humana. Esta situação ocorre, nas palavras de Verena Alberti ${ }^{40}$, no momento em que é encontrada a "[.... 'vivacidade' do passado, a possibilidade de revivê-lo pela experiência do entrevistado". Resgatar estas memórias significa, portanto, compreender o passado por meio dos fatos pretéritos.

De certa forma, o indivíduo constrói sua biografia ao expor suas vivências, mas com ela não se confunde, pois o objetivo do pesquisador, mesmo que utilize apenas de uma história de vida, é "[...] captar o grupo, a sociedade de que ela é parte; busca encontrar a coletividade a partir do indivíduo" ${ }^{11}$. Ao contrário, "o biógrafo, mesmo que retrate a sociedade de que seu personagem participa, a faz com o intuito de compreender melhor a existência do biografado".

A história de vida se coloca, nesta perspectiva, entre o individual e o social e, a depender do enfoque dado pelo pesquisador, um ou outro aspecto terá maior acentuação. $\mathrm{O}$ aspecto individual se destina à busca das

\footnotetext{
${ }^{38}$ BOSI, Ecléa. O tempo vivo da memória: ensaios de psicologia social. 3. ed. São Paulo: Ateliê, 2003. p. 19.

39 COSTA, Fernando Braga da. Moisés e Nilce: retratos bibliográficos de dois garis. Um estudo de psicologia social a partir de observação participante e entrevistas. 2008. 403f. Tese (Doutorado em Psicologia). Instituto de Psicologia da Universidade de São Paulo. São Paulo, 2008. p. 21-22.

${ }^{40}$ ALBERTI, Verena. Ouvir contar: textos em história oral. Rio de Janeiro: FGV, 2004. p. 14.

${ }^{41}$ QUEIROZ, Maria Isaura Pereira de. Variações sobre a técnica de gravador no registro da informação viva. São Paulo: T. A. Queiroz, 1991. p. 10.
} 
[...] particularidades que singularizam o indivíduo, delineia-se o caminho seguido na formação de sua personalidade através do emaranhado das relações variadas tecidas pela sua coletividade, e é o produto final, considerado como único, que se quer compreender e explicar ${ }^{42}$.

Pelo aspecto social, o emprego da história de vida procura, no informante, as "[...] marcas de seu grupo étnico, de sua camada social, de sua sociedade global - vários níveis que apresentam estruturas, hierarquias, valores ora harmoniosos, ora em desacordo, o que tudo se reflete no seu interior" ${ }^{\text {”3 }}$.

Em muitos casos, o emprego deste procedimento metodológico é considerado

[...] um ponto inicial privilegiado porque permite ao informante retomar sua vivência de forma retrospectiva, com uma exaustiva interpretação. Nela geralmente acontece a liberação de um pensamento crítico reprimido e que muitas vezes nos chega em tom de confidência ${ }^{44}$.

A história de vida se destina, neste sentido, ao resgate de trajetórias de vida e funciona, em muitos casos, como um verdadeiro repositório para a "[...] 'memória' de algo que se perderia com o desaparecimento de pessoas mais velhas $[\ldots]$ "..45. Dada a riqueza dos relatos obtidos por meio desta técnica, a investigação dificilmente se esgota num único encontro, isso porque eles não devem ser muito longos em razão do cansaço dos interlocutores, o qual pode comprometer a qualidade da investigação.

Como reflexo desta situação, muitos pesquisadores optam por trabalhar com um número reduzido de histórias de vida, pois além do tempo dispendido para a realização das próprias entrevistas, devem ser contabilizados o tempo para a transcrição e, sobretudo, o volume de informações colhidas que farão parte da análise. É uma investigação extensa que demanda esforço do pesquisador e, em razão disto,

\footnotetext{
$\overline{42}$ QUEIROZ, Maria Isaura Pereira de. Variações sobre a técnica de gravador no registro da informação viva. São Paulo: T. A. Queiroz, 1991. p. 21.

${ }^{43}$ Idem.

${ }^{44}$ CRUZ NETO, Octavio. O trabalho de campo como descoberta e criação. In: DESLANDES, Suely Ferreira; CRUZ NETO, Octavio; GOMES, Romeu; MINAYO, Maria Cecilia de Souza (org.). Pesquisa social: teoria, método e criatividade. Petrópolis: Vozes, 1994. p. 59.

${ }^{45}$ QUEIROZ, Maria Isaura Pereira de. Variações sobre a técnica de gravador no registro da informação viva. São Paulo: T. A. Queiroz, 1991. p. 18.
} 
tornou-se usual pesquisas nas ciências sociais que utilizem uma ou duas histórias de vida.

Se a entrevista na sua forma mais simplificada já requer uma aproximação entre os realizadores da técnica, pois ambas as modalidades, história de vida completa - que retrata todo o conjunto da experiência vivida - quanto a história de vida tópica - que focaliza uma etapa ou um determinado setor da experiência em questão ${ }^{46}$ - prescindem de certo grau de confiabilidade. Ao expor suas experiências de vida, os participantes revelam, quando atingido a finalidade da história de vida, sua essência.

Compreende-se, então, a história de vida como uma noção mais aprofundada da entrevista por meio de um diálogo impulsionado, mas não delimitado pelo pesquisador. Requer-se, igualmente, que o pesquisador lance um olhar cuidadoso sobre os movimentos e as expressões utilizadas para que as memórias do participante lhe sejam reveladas nos mínimos detalhes, os quais serão importantes para a análise em conjunto da pesquisa.

\subsection{OBSERVAÇÃO PARTICIPANTE}

O terceiro tipo de pesquisa é a observação participante, também denominada por alguns autores como pesquisa-ação ou pesquisa participante e, por outros, tratadas como técnicas de pesquisa distintas. Michel Thiollent ${ }^{47}$, por exemplo, defende que as expressões não são sinônimas, "[...] porque a pesquisa-ação, além da participação, supõe uma forma de ação planejada de caráter social, educacional, técnico ou outro, que nem sempre se encontra em propostas de pesquisa participante". No entanto, o mesmo autor opta por não aprofundar esta distinção, mas apenas considerar que ambas "[...] procedem de uma mesma busca de alternativas ao padrão de pesquisa convencional”48 ${ }^{4}$ que também consiste na opção do presente estudo.

Muito utilizada pelos pesquisadores da antropologia,

a técnica de observação participante foi introduzida na pesqui-

\footnotetext{
${ }^{46}$ CRUZ NETO, Octavio. O trabalho de campo como descoberta e criação. In: DESLANDES, Suely Ferreira; CRUZ NETO, Octavio; GOMES, Romeu; MINAYO, Maria Cecilia de Souza (org.). Pesquisa social: teoria, método e criatividade. Petrópolis: Vozes, 1994. p. 58-59.

${ }^{47}$ THIOLLENT, Michel. Metodologia da pesquisa-ação. 8. ed. São Paulo: Cortez, 1998. p. 7.

48 THIOLLENT, Michel. Metodologia da pesquisa-ação. 8. ed. São Paulo: Cortez Ed., 1998. p. 7
} 
sa social pelos antropólogos no estudo das chamadas "sociedades primitivas". A partir daí passou a ser utilizada também pelos antropólogos nos estudos de comunidades e de subculturas específicas. Mais recentemente passou a ser adotada como técnica fundamental nos estudos designados como "pesquisa participante" $"$.

Tem por principal característica a interação entre o pesquisador e os membros das situações investigadas ${ }^{50}$, isso porque ela é um facilitador de análise da realidade social, na medida em que proporciona um contato ativo entre o investigador e o seu objeto. É possível, por meio da observação participante, a construção de "[...] um retrato rico e detalhado da vida humana, um quadro que é interessante e potencialmente repleto de informações" ${ }^{\text {. }}$.

Oportuniza-se, para o sujeito pesquisador, a vivência por determinado período daquela realidade específica de maneira que ele possa compreender melhor as variáveis da situação a qual ele se propõe a trabalhar. É uma maneira de conceder espaço de fala, estudo, para aqueles indivíduos "analisados", no sentido de permitir que eles saiam - no âmbito da pesquisa científica - da condição de "objetos de pesquisa".

Sobre esta situação, Ines de Oliveira Ramos ${ }^{52}$ ressalta que

[...] quando o pesquisador tenta compreender como as variadas situações são interpretadas por diversas pessoas, ele não busca uma realidade única, mas a pluralidade de vozes, inclusive a sua própria voz (a do pesquisador), mesmo que contraditórias entre si. O foco do olhar do pesquisador neste caso reside nos processos e não nos produtos, suscitando perguntas do tipo "como" e "por quê".

Importante ressaltar o grau de complexidade desta técnica, uma vez que ela "[...] coloca duplo desafio: pesquisar e participar" ${ }^{33}$ para o pesquisador. Contudo, a

\footnotetext{
${ }_{49}$ GIL, Antonio Carlos. Métodos e técnicas de pesquisa social. São Paulo: Atlas, 1999. p. 103.

${ }^{50}$ GIL, Antonio Carlos. Como elaborar projetos de pesquisa. 4. ed. São Paulo: Atlas, 2002. p. 55.

${ }^{51}$ MOREIRA, Herivelto; CALEFFE, Luiz Gonzaga. Metodologia da pesquisa para o professor pesquisador. 2. ed. Rio de Janeiro: Lamparina, 2008. p. 88.

52 RAMOS, Ines de Oliveira. Educação especial e a Superintendência Regional de Educação de Cariacica: um diálogo possível. 2011. 247f. Tese (Programa de Pós-Graduação em Educação) - Universidade Federal do Espírito Santo, Vitória, 2011. p. 92.

${ }^{53}$ DEMO, Pedro. Metodologia científica em ciências sociais. 3. ed. São Paulo: Atlas, 1995. p. 240.
} 
sua realização é de extrema relevância no que tange aos temas sociais, possibilitando a captação de "[...] uma variedade de situações ou fenômenos que não são obtidos por meio de perguntas, uma vez que, observados diretamente na própria realidade, transmitem o que há de mais imponderável e evasivo na vida real" ${ }^{\text {‘4 }}$.

Alguns traços precisam ser observados na execução desta técnica, tais como

a) realização perceptível do fenômeno participativo; sem organização comunitária, a rigor, não sai autodiagnostico;

b) produção de conhecimento, também a partir da prática, evitando-se simples ativismo;

c) equilíbrio entre forma e conteúdo; não há por que desprezar levantamentos empíricos, construções científicas lógicas, como não há sentido em submeter a prática ao método, tornando este fim de si mesmo;

d) decisão política do pesquisador de correr o risco da identificação ideológica com a comunidade, para não desaparecer da cena na primeira batalha, abandonando-a à sua própria sorte, o que seria, de novo, fazê-la de cobaia;

e) ao lado da competência formal acadêmica, é fundamental experiência em desenvolvimento comunitário - teoria e prática ${ }^{55}$.

É muito comum que esta técnica de pesquisa seja utilizada em concomitância à entrevista ou mesmo à história de vida, porque ao mesmo tempo que permite o conhecimento dos mínimos detalhes revelados pelo ambiente ou pela atividade observada, possibilita ao pesquisador realizar uma ambientação prévia e, com isso, facilitar o emprego das técnicas de diálogo com os integrantes da análise.

Não é nem de longe uma tarefa fácil, pois este tipo de imersão no campo requer um esforço, tanto do pesquisador no sentido de construir um canal efetivo de comunicação e igualmente de aceitação, quanto dos integrantes da comunidade ao permitirem, por exemplo, que um "desconhecido" analise seu passo a passo de trabalho, convivência dentre outras atividades e comportamentos. A dificuldade está nos dois lados, pois "invadir" a privacidade destas pessoas requer certo grau de empatia e aceitabilidade do grupo investigado.

\footnotetext{
${ }^{54}$ CRUZ NETO, Octavio. O trabalho de campo como descoberta e criação. In: DESLANDES, Suely Ferreira; CRUZ NETO, Octavio; GOMES, Romeu; MINAYO, Maria Cecilia de Souza (org.). Pesquisa social: teoria, método e criatividade. Petrópolis: Vozes, 1994. p. 59-60.

55 DEMO, Pedro. Metodologia científica em ciências sociais. 3. ed. São Paulo: Atlas, 1995. p. 240-241.
} 
Observa-se, então, que existem níveis de aproximação com a realidade partindo de uma modalidade mais simples, a entrevista, aumentando o grau de complexidade para o pesquisador, com a história de vida, haja vista a necessidade de desenrolar o novelo em que as memórias são apresentadas para o interlocutor. E, no último nível proposto neste trabalho, foi a observação participante, a qual exige um grau elevado de aproximação, tanto com o ambiente investigado, quanto com os próprios sujeitos da investigação, uma vez que requer um tempo maior de contato entre eles para que seja atingida maior completude na análise.

Sobre a importância de se adequar a técnica de pesquisa ao objeto de análise, Queiroz ${ }^{56}$ pontua que

Não tem sentido, nas ciências sociais, tomar-se partido por este ou aquele procedimento, tanto mais que a obtenção de dados de fontes variadas, que enriquecem uma pesquisa, determina a necessidade de se utilizarem técnicas também variadas. A querela é vã; o importante é saber escolher a técnica adequada ao tipo de problema, à especificidade do dado e ao momento preciso da investigação.

Portanto, apesar do grau de complexidade contido na execução das técnicas de pesquisa que proporcionam a imersão do pesquisador ao campo, é preciso buscar alternativas à utilização da pesquisa bibliográfica no direito, sendo as técnicas apresentadas algumas dentre as várias possibilidades científicas existentes.

\section{RESOLUÇÃO No 466/2012 E AS EXIGÊNCIAS DO COMITÊ DE ÉTICA NAS PES- QUISAS QUE ENVOLVEM SERES HUMANOS}

A preocupação com a fixação de padrões éticos é um assunto que atinge as pesquisas de todas as áreas do conhecimento. E com o direito, enquanto subárea das ciências sociais, não poderia ser diferente, pois para que a produção científica seja respeitada é necessário certo rigor na sua realização.

Trata-se de condutas normativas que devem ser observadas pelos pesquisadores que optarem pelo emprego de certas técnicas de pesquisa: todos aqueles procedimentos que envolverem, em menor ou maior grau, seres humanos. Para garantir

\footnotetext{
${ }^{56}$ QUEIROZ, Maria Isaura Pereira de. Variações sobre a técnica de gravador no registro da informação viva. São Paulo: T. A. Queiroz, 1991. p. 20.
} 
que não haja, por exemplo, situações que violem a integridade física e psíquica dos participantes da pesquisa, é necessário o crivo dos órgãos de controle deste tipo de produção científica.

Apesar de tais exigências serem muito comuns às ciências naturais e biológicas em virtude de elas terem por essência o envolvimento direto de pessoas e de animais com os procedimentos científicos, para o direito elas são relativamente novas. Requer-se certa adaptação, pois não é comum, nesta área, a utilização de técnicas variadas. No entanto, as transformações da pesquisa jurídica exigiram uma modificação significativa no controle efetuado pelas pesquisas, uma vez que "o conhecimento confere poder e, portanto, ao coletarem dados, os pesquisadores devem atentar para os possíveis efeitos que a participação na pesquisa pode ter nos participantes" 57 .

Por meio da resolução n. 466, editada em 12 de dezembro de 2012, pelo Conselho Nacional de Saúde, foram estabelecidas normas e diretrizes regulamentando as investigações que envolvam seres humanos. Com isso, a aplicação destas determinações legais não é restrita aos pesquisadores das áreas da saúde, uma vez que a finalidade de sua criação é reduzir os riscos aos quais os participantes da investigação estejam, porventura, expostos, o que se aplica às pesquisas em diversas áreas, desde que contenham nas características estabelecidas pela legislação.

Determinou-se que cada instituição de ensino deve criar o seu próprio Comitê de Ética em Pesquisa (CEP), o qual juntamente com a Comissão Nacional de Ética em Pesquisa (CONEP/CNS/MS), do Conselho Nacional de Ética em Pesquisa formarão o sistema CEP/CONEP. Este sistema é responsável por um "[...] trabalho cooperativo que visa, especialmente, à proteção dos participantes de pesquisa do Brasil, de forma coordenada e descentralizada por meio de um processo de acreditação" ${ }^{\text {"58 }}$.

Neste sentido, tanto os pesquisadores responsáveis pela pesquisa, quanto seus respectivos projetos deverão ser cadastrados numa plataforma virtual de âmbito nacional, denominada Plataforma Brasil ${ }^{59}$. Nesta primeira etapa, os pesquisadores deverão preencher questionários detalhados dos principais pontos da pesquisa a fim de dar um panorama geral acerca da investigação. Serão exigidas informações específicas da pesquisa, como o resumo, a hipótese, os objetivos, a delimitação da

\footnotetext{
${ }^{57}$ SOMEKH, Bridget; et al. Pesquisa nas ciências sociais. In: SOMEKH, Bridget; LEWIN, Cathy. (org.) Teoria e Métodos de Pesquisa Social. Tradução de Ricardo A. Rosenbusch. Vozes: Petrópolis, 2015. p. 29-30.

${ }^{58}$ BRASIL. Resolução n. 466, de 12 de dezembro de 2012. Disponível em: http://bvsms.saude.gov.br/bvs/saudelegis/cns/2013/res0466_12_12_2012.html. Acesso em: 16 out. 2017.

${ }^{59}$ As informações acerca do cadastro, dos Comitês de Ética poderão ser encontradas no seguinte endereço eletrônico: http://plataformabrasil.saude.gov.br/login.jsf.
} 
amostra, a área de abrangência da pesquisa, a metodologia empregada para análise dos dados obtidos, indicação dos riscos e dos benefícios da pesquisa para os seus integrantes, além do referencial teórico que será utilizado para a produção científica.

Para finalizar esta etapa, exige-se que seja anexado o projeto de pesquisa na íntegra, os questionários que serão aplicados aos participantes, no caso de entrevistas, bem como o Termo de Livre Consentimento (TCLE). De acordo com a resolução n. 466/2012, o TCLE refere-se ao documento que precisa ser apresentado, pelo pesquisador responsável, a todos os participantes da pesquisa individualmente. A sua finalidade é reforçar o compromisso ético da pesquisa e do pesquisador com os dados colhidos no processo de investigação e esclarecer aos integrantes do que se trata a pesquisa e a sua participação.

O termo também deve ser expresso ao informar, aos interlocutores, a proibição quanto à sua identificação. Ciente da sua participação e dos contornos da pesquisa, o indivíduo terá condições de anuir a sua participação e à divulgação de cunho científico de suas falas quando a pesquisa se utilizar da técnica de entrevistas, por exemplo.

Neste caso, é possível que o pesquisador utilize a transcrição de trechos extraídos das conversas no resultado final do seu trabalho, desde que haja a expressa anuência dos entrevistados. Uma alternativa para que não haja a identificação dos interlocutores é a atribuição de nomes de objetos a eles, apelidos, dentre outras formas, mas nenhuma delas deve revelar sua identidade.

Com vistas a ser compreendido pelo participante, a resolução estabelece que

[...] documento no qual é explicitado o consentimento livre e esclarecido do participante e/ou de seu responsável legal, de forma escrita, devendo conter todas as informações necessárias, em linguagem clara e objetiva, de fácil entendimento, para o mais completo esclarecimento sobre a pesquisa a qual se propõe participar; ${ }^{60}$

Feita a submissão dos projetos de pesquisa à Plataforma Brasil, estes serão encaminhados aos respectivos comitês de ética da instituição de ensino à qual o pesquisador responsável está vinculado para sua correspondente análise. Na falta

${ }^{60}$ BRASIL. Resolução n. 466, de 12 de dezembro de 2012. Disponível em: http://bvsms.saude.gov.br/bvs/saudelegis/cns/2013/res0466_12_12_2012.html. Acesso em: 16 out. 2017. 
de um "[...] CEP na instituição proponente ou em caso de pesquisador sem vínculo institucional, caberá à CONEP a indicação de um CEP para proceder à análise da pesquisa dentre aqueles que apresentem melhores condições para monitorá-la" ${ }^{* 1}$.

Conforme a resolução n. 466/2012, os comitês de ética constituem-se, assim, para a defesa dos "[...] interesses dos participantes da pesquisa em sua integridade e dignidade e para contribuir no desenvolvimento da pesquisa dentro de padrões éticos" ${ }^{\prime 2}$ como colegiados interdisciplinares e independentes. Isso significa que, ao exercerem a função de análise do projeto de pesquisa que lhe foi submetido, eles devem julgar as questões éticas que nele estão envolvidas com o objetivo de proteger não só a integridade dos que nela estão envolvidos, mas sobretudo garantir a cientificidade da investigação.

\section{CONSIDERAÇÕES FINAIS}

Ao final deste estudo, pode-se afirmar que chegamos num nível de complexidade social que a pesquisa restrita ao universo bibliográfico por si só não se apresenta mais como suficiente, principalmente, quando diz respeito a temas eminentemente sociais. Aproximar-se, então, do "objeto de pesquisa" - compreendendo, sobretudo, os sujeitos de direitos que fazem parte daquela situação social - faz-se necessário para conferir maior fidedignidade ao discurso da academia jurídica.

É importante, então, que o pesquisador se disponha a conhecer mais de perto essa realidade a qual ele se propõe a estudar, já que é visível que o direito positivo não dá conta da complexidade da realidade, sendo a pesquisa um importante instrumento de mudança na forma pela qual os próprios profissionais desta área trabalham com a realidade que lhe é posta à análise.

Com a finalidade de quebrar essa lógica da permanência histórica, é preciso buscar modelos que vão além da pesquisa meramente bibliográfica, como os exemplos apresentados neste estudo, quais sejam: entrevista, história de vida e observação participante. Assim, numa tentativa de modificar o cenário em que as pesquisas no direito continuam sendo realizadas, desde a criação dos primeiros cursos no Brasil, é preciso conhecer inúmeras outras possibilidades passíveis de utilização nas

\footnotetext{
${ }^{61}$ BRASIL. Resolução n. 466, de 12 de dezembro de 2012. Disponível em: http:/bvsms.saude.gov.br/bvs/saudelegis/cns/2013/res0466_12_12_2012.html. Acesso em: 16 out. 2017.

${ }^{62}$ BRASIL. Resolução n. 466, de 12 de dezembro de 2012. Disponível em: http://bvsms.saude.gov.br/bvs/saudelegis/cns/2013/res0466_12_12_2012.html. Acesso em: 16 out. 2017.
} 
ciências sociais, em especial, no âmbito jurídico.

Pelo fato de que a pesquisa jurídica lida com pessoas e acontecimentos sociais, torna-se imprescindível a atuação dos comitês de ética. Tendo como fonte legislativa a resolução $n^{0} 466 / 2012$, estes órgãos atuam como forma de balizar este tipo de investigação. Isso porque, as pesquisas que lidam de maneira direta com seres humanos ainda é uma prática incipiente no direito e necessita de maior rigor metodológico no seu modus operandi.

A pesquisa é, então, um pilar fundamental na desconstrução deste ensino tradicional fundado no dogmatismo, que tem como base a legislação existente, a qual é notável não ser capaz de tutelar a complexidade das relações sociais, já que desde a sua criação no Brasil, defende-se a crise deste ensino. Mudar a forma de produzir a ciência do direito constitui-se numa importante tentativa de superar a crise que o ensino jurídico se encontra há tantos anos.

\section{REFERÊNCIAS}

ALBERTI, Verena. Ouvir contar: textos em história oral. Rio de Janeiro: FGV, 2004.

BOSI, Ecléa. O tempo vivo da memória: ensaios de psicologia social. 3. ed. São Paulo: Ateliê Editorial, 2003.

BRASIL. Constituição Federal de 1988. Disponível em: http://www.planalto.gov. br/ccivil_03/constituicao/constituicao.htm. Acesso em: 23 maio 2019.

BRASIL. Resolução n. 466, de 12 de dezembro de 2012. Disponível em: http:// bvsms.saude.gov.br/bvs/saudelegis/cns/2013/res0466_12_12_2012.html. Acesso em: 16 out. 2017.

COSTA, Fernando Braga da. Homens invisíveis: relatos de uma humilhação social. São Paulo: Globo, 2004.

COSTA, Fernando Braga da. Moisés e Nilce: retratos bibliográficos de dois garis. Um estudo de psicologia social a partir de observação participante e entrevistas. 2008. 403f. Tese (Doutorado em Psicologia) - Instituto de Psicologia da Universidade de São Paulo, São Paulo, 2008. 
COSTA, Everton de Brito Oliveira; RAUBER, Pedro. História da educação: surgimento e tendências atuais na universidade no Brasil. Revista Jurídica UNIGRAN. Dourados, MS, v. 11, n. 21, Jan./Jun, 2009. p. 241-253.

CRUZ NETO, Octavio. O trabalho de campo como descoberta e criação. In: DESLANDES, Suely Ferreira; CRUZ NETO, Octavio; GOMES, Romeu; MINAYO, Maria Cecilia de Souza (org.). Pesquisa social: teoria, método e criatividade. Petrópolis: Vozes, 1994.

DEMO, Pedro. Metodologia científica em ciências sociais. 3. ed. São Paulo: Atlas, 1995.

FRANCISCHETTO, Gilsilene Passon P. Em busca de novos saberes: uma aproximação entre o ensino jurídico e a pedagogia. In: FRANCISCHETTO, Gilsilene Passon P. Ensino jurídico e pedagogia: em busca de novos saberes. Curitiba. CRV, 2010. p. 13-52.

DUARTE, Ícaro de Souza; CRUZES, Maria Soledad Soares. A metodologia da pesquisa no Direito e Boaventura de Sousa Santos. Cadernos de Ciências Sociais Aplicadas, Vitória da Conquista, n. 8, p. 27-45, 2009.

GIL, Antonio Carlos. Como elaborar projetos de pesquisa. 4. ed. São Paulo: Atlas, 2002.

GIL, Antonio Carlos. Métodos e técnicas de pesquisa social. São Paulo: Atlas, 1999.

LAVILLE, Christian; DIONNE, Jean. A construção do saber: manual de metodologia da pesquisa em ciências humanas. Tradução de Heloísa Monteiro e Francisco Settineri. Porto Alegre: Artmed, 1999.

MARCONI, Marina de Andrade; LAKATOS, Eva Maria. Metodologia Científica. 4. ed. São Paulo: Atlas, 2004.

MASETTO, Marcos. Professor universitário: um profissional da educação na atividade docente. In.: MASETTO, Marcos. Docência na universidade. 6. ed. Campinas: Papirus, 2003. 
1994. Disponível em: http://portal.mec.gov.br/sesu/arquivos/pdf/dir_dire.pdf. Acesso em: 23 maio 2019.

MINISTÉRIO DA SAÚDE. Plataforma Brasil. Disponível em: http://plataformabrasil.saude.gov.br/login.jsf. Acesso em: 23 maio 2019.

MOREIRA, Herivelto; CALEFFE, Luiz Gonzaga. Metodologia da pesquisa para o professor pesquisador. 2. ed. Rio de Janeiro: Lamparina, 2008.

QUEIROZ, Maria Isaura Pereira de. Variações sobre a técnica de gravador no registro da informação viva. São Paulo: T. A. Queiroz, 1991.

RAMOS, Ines de Oliveira. Educação especial e a Superintendência Regional de Educação de Cariacica: um diálogo possível. 2011. 247f. Tese (Programa de Pós-Graduação em Educação) - Universidade Federal do Espírito Santo, Vitória, 2011.

SANTOS, Boaventura de Sousa Santos. Um discurso sobre as ciências. 5. ed. São Paulo: Cortez, 2008.

SCHOSTAK, John; BARBOUR, Rosaline S. Entrevista e grupos-alvo. In: SOMEKH, Bridget; LEWIN, Cathy. (org.) Teoria e Métodos de Pesquisa Social. Tradução de Ricardo A. Rosenbusch. Vozes: Petrópolis, 2015. p. 99-107.

SOMEKH, Bridget et al. Pesquisa nas ciências sociais. In: SOMEKH, Bridget; LEWIN, Cathy. (org.) Teoria e Métodos de Pesquisa Social. Tradução de Ricardo A. Rosenbusch. Vozes: Petrópolis, 2015. p. 27-44.

THIOLLENT, Michel. Metodologia da pesquisa-ação. 8. ed. São Paulo: Cortez, 1998.

Recebido em: 03/09/2018 